\title{
Influence of thermal stratification and storms on acoustic telemetry detection efficiency: a year-long test in the US Southern Mid-Atlantic Bight
}

\author{
Michael H. P. O’Brien * (1) and David H. Secor
}

\begin{abstract}
Background: The detection efficiency of ultrasonic transmitters is seasonally variable, requiring long-term studies to evaluate key environmental features that mask, alter speed, bend, or reflect transmissions. The US Southern Mid-Atlantic Bight shelf is characterized by a strong summer thermocline capping remnant winter water, known as the Cold Pool, and a well-mixed water column in other seasons. To investigate the effects of interactions between temperature stratification and storm-induced noise on transmission detectability, we conducted a year-long range test of $69-\mathrm{kHz}$ acoustic transmitters in the bottom waters of the US Southern Mid-Atlantic Bight. We used generalized additive models and cross-validation to develop and evaluate a predictive model of detection efficiency and visualize variability in detection distance throughout the year of deployment.
\end{abstract}

Results: The most-predictive model contained the effects of temperature stratification and ambient noise, predicting that stratification results in a 33\% increase in detectability and 56\% increase in detection distance. The model had an overall error rate of $17.1 \%$ and an $18.7 \%$ error at a distance of $800 \mathrm{~m}$, predicting $17 \%$ detectability at median ambient noise when the water column was not stratified and $>50 \%$ when the difference between surface and bottom temperatures was greater than $4.2^{\circ} \mathrm{C}$. The distance at $50 \%$ detectability increased with the formation of the Cold Pool during spring, increasing by nearly $300 \mathrm{~m}$ over 3 days. All seasons were associated with storm-induced reductions in overall detectability and distance at $50 \%$ detectability.

Conclusion: Thermal stratification within the Southern Mid-Atlantic Bight increases bottom water ultrasonic transmitter detection distance and reduces the impact of surface noise. This effect leads to a seasonal increase in detection distance from the late-spring through the summer. To our knowledge, this study is the first to report and quantify an increase in detection range as a result of temperature stratification, likely due to placing transmitters and receivers on the same side of a strong thermocline.

Keywords: Acoustic telemetry, Range testing, Detection efficieny, US mid-Atlantic Bight, Cold Pool, Telemetry array, Thermal stratification

${ }^{*}$ Correspondence: obrien@umces.edu

Chesapeake Biological Laboratory, University of Maryland Center

for Environmental Science, Solomons, MD, USA

\section{Background}

As the prevalence of biotelemetry in long-term monitoring of fish migration and habitat use increases, so too should the evaluation of temporally varying detection probability. Due to the large variation in sound production and attenuation across environments, understanding

c) The Author(s) 2021. This article is licensed under a Creative Commons Attribution 4.0 International License, which permits use, sharing, adaptation, distribution and reproduction in any medium or format, as long as you give appropriate credit to the original author(s) and the source, provide a link to the Creative Commons licence, and indicate if changes were made. The images or other third party material in this article are included in the article's Creative Commons licence, unless indicated otherwise in a credit line to the material. If material is not included in the article's Creative Commons licence and your intended use is not permitted by statutory regulation or exceeds the permitted use, you will need to obtain permission directly from the copyright holder. To view a copy of this licence, visit http://creativeco mmons.org/licenses/by/4.0/. The Creative Commons Public Domain Dedication waiver (http://creativecommons.org/publicdomain/ zero/1.0/) applies to the data made available in this article, unless otherwise stated in a credit line to the data. 
of detection ranges is necessary to correctly interpret acoustic telemetry data [1]. The detection probability of ultrasonic transmitters utilized in acoustic biotelemetry, hereafter referred to as detectability, varies with seasonal and event-scale physical changes in the environment [2]; still, many studies do not address temporal changes in detection probability and assume a constant value or apply previously calculated values to different types of environments [1,3]. In gated and gridded designs of receivers, changes in detection probability can alternatively occlude or exaggerate assessed presence of telemetered animals if detection ranges are not adequately known [4]. Indeed, there has been an increase in studies incorporating long-term range testing to either directly scale results [5] or to inform detection range due to local features $[6,7]$.

Acoustic transmitters produce coded ultrasonic signals that are detected and logged by receivers placed in locations selected to encounter the target organism. Ultrasonic transmission distance is variable and dependent on initial transmission strength and the physical properties of the water column [8]. At a given distance and transmission strength, detectability is a function of signal loss due to spreading and sound attenuation in water. The speed of sound in seawater, and thus the propensity for detection, increases with increasing temperature, salinity, and depth [9], though, in shallow-water acoustics, depth is often ignored in favor of the dominant effects of temperature and salinity [10]. Additionally, summer temperature effects dominate over salinity impacts in marine shelf environments due to the comparatively larger temperature range.

Inherent physical and biological processes within the area of investigation can create masking noise, sound reflection, or sound absorption at or near the tag's transmission frequency, reducing the detectability of a transmission signal above the ambient sound regime. In shallow water, signal and noise can reflect off the surface and bottom boundaries multiple times, with differential absorption occurring with each bottom contact [11]. Periods of rain, wind, waves [8], and boating traffic [12] produce cavitation, the collapse of which emits diffuse ultrasonic noise from the surface. Near the bottom, organisms such as snapping shrimp [13] produce further ultrasonic noise. Internal boundaries, like multilaminar flow [14], internal waves [11], local fronts [10], and stratification [15] variably reflect, attenuate, or increase both signal and noise propagation through the water column according to their strength and origin.

To evaluate both seasonal- and event-scale changes in detection range within a key migration corridor for elasmobranchs, fishes, and turtles (inner and mid-shelf waters $<50 \mathrm{~m}$ depth) [16, 17], we evaluated telemetry detection ranges over a 12-month period in a dynamic shallow shelf system: the Southern Mid-Atlantic Bight (SMAB). The SMAB is well-mixed in winter months via increased wind stress and by buoyancy differences arising from cold surface water overlying warmer, saline bottom water fed by the Gulf Stream and continental slope [18]. A seasonal thermocline, fueled by a combination of advection of bottom water from higher latitudes and surface heating [19], overwhelms salinity-driven mixing and forms in mid- to late-April, strengthening through the summer months. This cold bottom water, known as the Mid-Atlantic Cold Pool, persists in the shelf waters of the SMAB into late-summer when it is rapidly destroyed through surface mixing via tropical storms, offshore advection, and reduced thermal input [20-22]. After destruction of the Cold Pool, buoyancy-driven mixing once again becomes the dominant thermohaline process and lasts through the winter.

At two sites representing common nearshore $(17 \mathrm{~m})$ and mid-shelf $(28 \mathrm{~m})$ conditions at the western edge of the SMAB Cold Pool, we conducted a near-bottom 12-month range test for $69-\mathrm{kHz}$ transmissions (Fig. 1). This period was interspersed with multiple wind events and over a complete cycle of Cold Pool formation, destruction, and winter mixing. At each site, three receivers (VR2AR, VEMCO Ltd) were placed at 0, 250, and $800 \mathrm{~m}$ distances to represent the range of a priori-assumed detection distances [5]. We modeled the response of receiver detectability to ambient noise at $69 \mathrm{kHz}$ during periods of strong and weak thermal stratification produced by the Cold Pool lifecycle. As the Cold Pool introduces a density boundary that is likely to affect the propagation of sound, we hypothesize that thermal stratification associated with Cold Pool presence will have a greater effect on detectability than considering temperature or ambient noise, alone.

\section{Results \\ Mid-Atlantic cold pool}

The study area remained well-mixed $(\Delta T \approx 0)$ from December 19, 2017 until mid-April 2018; thereafter vernal heating and a reduction in high-wind events resulted in a gradual rise in thermal stratification and subsequent Cold Pool formation in nearshore and mid-shelf waters (Fig. 2). The Cold Pool became fully formed in early May, with a period of rapid stratification of $1.1{ }^{\circ} \mathrm{C} \Delta \mathrm{T}$ day ${ }^{-1}$ occurring from May 2 through May 5. After the onset of stratification, $\Delta \mathrm{T}$ ranged from $0.8-12.9{ }^{\circ} \mathrm{C}$ at the nearshore site and $1.7-17.4{ }^{\circ} \mathrm{C}$ at the mid-shelf site until the Cold Pool rapidly collapsed from September 7-10; stronger thermal stratification consistently occurred at the deeper mid-shelf site as compared to the nearshore site. Acute periods of partial-to-complete destratification 


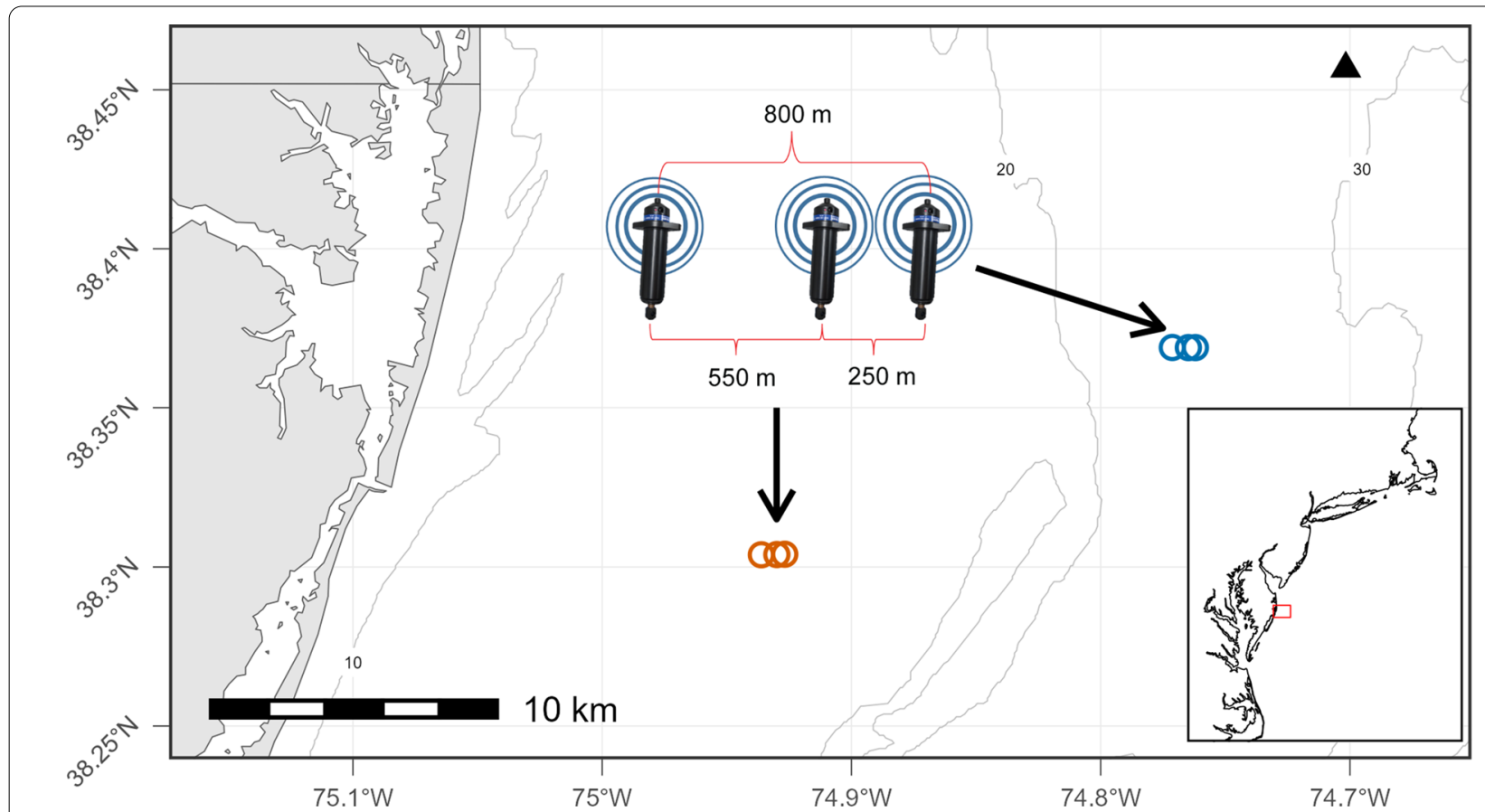

Fig. 1 Map of study sites and diagram of experimental array offshore of Maryland, USA with 10-m depth contours. Circles denote receiver locations of the mid-shelf (blue) and nearshore (orange) sites; the triangle denotes the location of recorded wind speeds. Inset shows the study location in reference to the U.S. mid-Atlantic coast
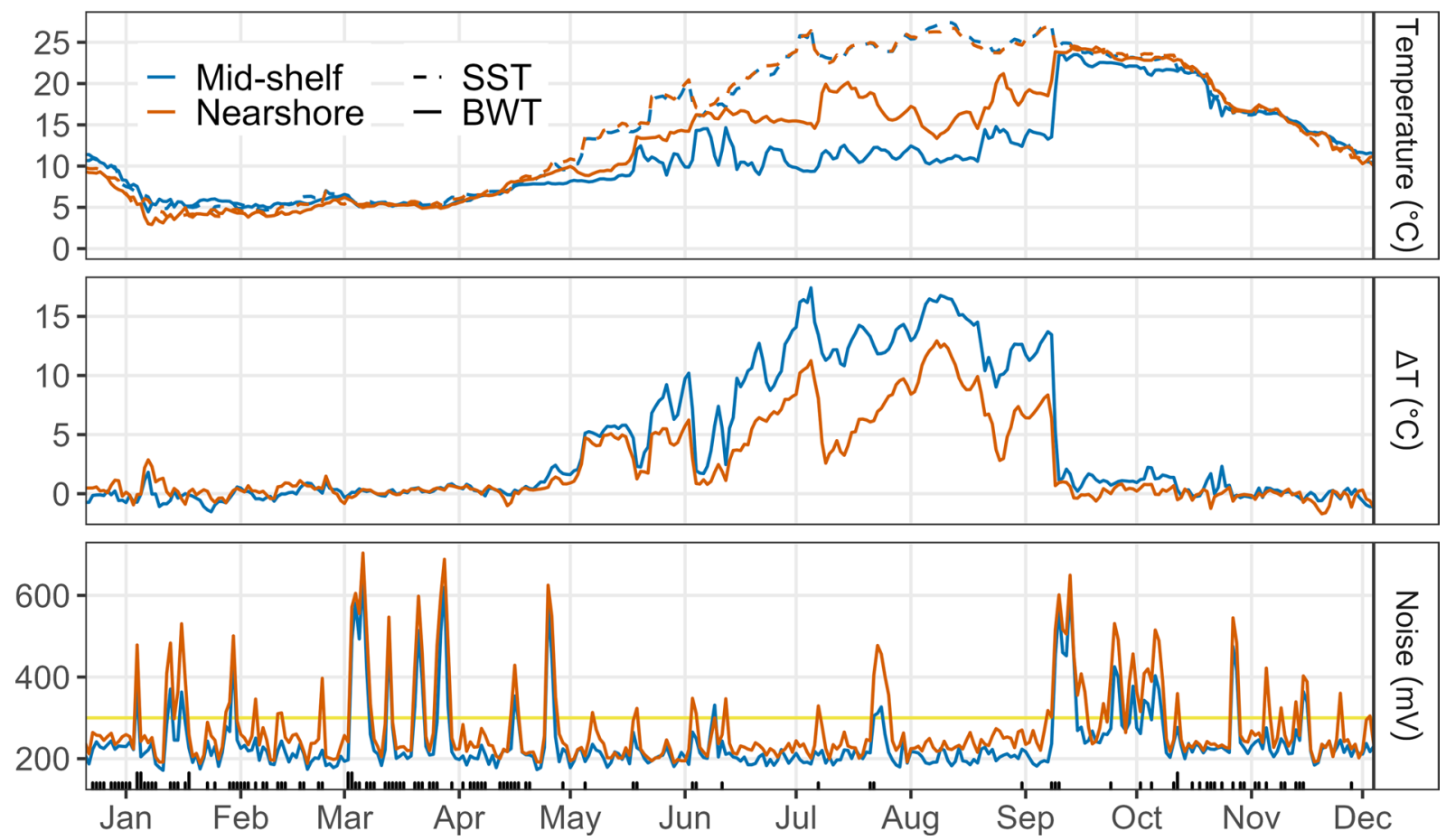

Fig. 2 Observed water temperature (surface: dashed line; and bottom: solid line), $\Delta T$, and ambient noise in the nearshore (orange) and mid-shelf (blue) sites. Yellow line demarcates noise levels above which detection range is likely to be reduced (300 mV, [24]). Rug denotes periods of winds greater than 6 (short line) and 8 (tall line) on the Beaufort Wind Scale (>10.7 m/s and $>17.2 \mathrm{~m} / \mathrm{s}$, respectively) 


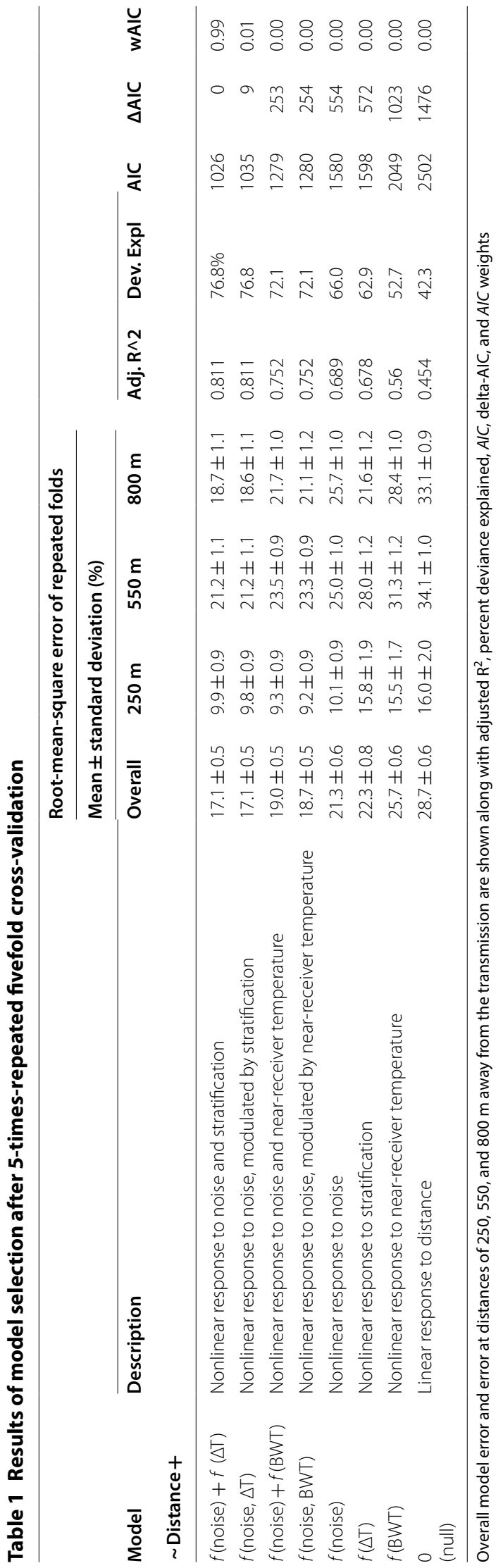


of nearshore waters are often associated with large wind events or tropical storms [23], and were observed on May 16-19, June 2-4, July 5-9, and August 19-24, 2018 where $\Delta \mathrm{T}$ decreased by $3.5-8.7^{\circ} \mathrm{C} \Delta \mathrm{T}$ over the course of several hours to several days.

Spikes in noise (measured as $\mathrm{mV}$ at $69 \mathrm{kHz}$ ) often co-occurred with high-wind storm events, including a period of five nor'easters in the months of March and April, a summer nor'easter on July 21, and an unnamed, late-summer wind event that resulted in the ultimate destratification of the water column in early September (Fig. 2). During the period of Cold Pool presence, ambient noise at $69 \mathrm{kHz}$ was significantly lower (ANOVA: $p<0.001$ ), and contained significantly fewer days in which transmissions were likely to be masked $(>300 \mathrm{mV}$, [24, 25]; Chi-square test: $p<0.001)$. This may also be attributed to a co-occurring reduction in storm activity rather than the presence of the Cold Pool, itself (Fig. 2).

\section{Observed and modeled detectability}

Observed detectability decreased with increasing distance from source, with detectability of $97.2 \pm 1.4 \%$ at $250 \mathrm{~m}, 73.4 \pm 22.0 \%$ at $550 \mathrm{~m}$, and $18.1 \pm 18.1 \%$ at $800 \mathrm{~m}$ (median \pm median absolute deviation). Detectability at distance varied between arrays, with median detectability of $95.8 \pm 2.8 \%$ and $97.9 \pm 1.4 \%$ at $250 \mathrm{~m}$; $59.0 \pm 33.4 \%$ and $81.8 \pm 14.7 \%$ at $550 \mathrm{~m}$; and $15.2 \pm 15.2 \%$ and $23.1 \pm 23.1 \%$ at $800 \mathrm{~m}$ in the nearshore and mid-shelf arrays, respectively.

The best-performing model of detectability contained the main effects of noise at $69 \mathrm{kHz}$ and the $\Delta \mathrm{T}$ index of stratification; the model that included their interaction performed similarly in terms of predictive strength (root-mean-square error; Table 1) still, this model was not selected according to Akaike Information Criterion (AIC). Both models were $11 \%$ more accurate in predicting detection frequency than considering distance alone (Table 1; the null model), and $4 \%$ more accurate than only considering noise. Models that included an index of temperature stratification performed $2 \%$ better than those that only considered bottom water temperature. Prediction performance lessened at the 550 and $800 \mathrm{~m}$ distances for all models, with the best model predicting $13-15 \%$ and $3-7 \%$ more-accurately than the distanceonly and distance-noise models, respectively.

The lowest detection probabilities at $800 \mathrm{~m}$ and a given value of ambient noise occurred when there was littleto-no temperature stratification $\left(\Delta \mathrm{T} \leq 0{ }^{\circ} \mathrm{C}\right.$; Fig. 3a, b). Detectability increased linearly as temperature stratification increased from 1.5 to $3.5{ }^{\circ} \mathrm{C} \Delta \mathrm{T}$, after which it began to level off and remained at relatively constant at values of $\Delta \mathrm{T}>4.2^{\circ} \mathrm{C}$. Site-specific estimates of detectability under median noise conditions significantly exceeded those under well-mixed conditions. When stratification exceeded $1.6{ }^{\circ} \mathrm{C} \Delta \mathrm{T}$, detectability was: nearshore, $11.2 \%$ [8 - 15.5\%] @ $0{ }^{\circ} \mathrm{C} \Delta \mathrm{T}$ and 21.5\% [15.9-28.4\%] @ $1.6{ }^{\circ} \mathrm{C} \Delta \mathrm{T}$; mid-shelf, 20.9\% [15.6-27.4\%] @ $0{ }^{\circ} \mathrm{C} \Delta \mathrm{T}$ and $36.3 \%$ [27.9-45.6\%] @ $1.6{ }^{\circ} \mathrm{C} \Delta \mathrm{T}$. Predicted detectability reached a maximum at $10.6{ }^{\circ} \mathrm{C} \Delta \mathrm{T}$, resulting in a global estimate of 58.5\% [95\% confidence interval: 27.5-83.9\%] and $28.0 \%$ detectability [10.0-57.8\%] under median and loud noise conditions, respectively. Global estimates of detectability under stratified conditions were not significantly greater than those estimated under destratified conditions, though this is likely over-conservative due to the high uncertainty associated with parameterizing a random effect with only two levels [26].

The marginal response of predicted detectability at $800 \mathrm{~m}$ to noise was "hockey-stick" shaped under both stratified (Fig. 3c) and destratified (Fig. 3d) conditions. Detectability exhibited a rapid decrease to low levels with increasing noise up to $300 \mathrm{mV}$ in stratified conditions $\left(-0.45 \% \mathrm{mV}^{-1}\right)$ and $250 \mathrm{mV}$ in unstratified conditions $\left(-0.39 \% \mathrm{mV}^{-1}\right)$, followed by a less-rapid decrease with increasing noise thereafter $\left(-0.06 \% \mathrm{mV}^{-1} ;-0.01 \%\right.$ $\mathrm{mV}^{-1}$ ). Site-specific estimates of detectability at $300 \mathrm{mV}$ were significantly greater under stratified conditions at both the nearshore (stratified: $17.9 \%$ [11.4-26.9\%]; unstratified: $3.8 \%$ [2.4-5.9\%]) and mid-shelf sites (31.2\% [20.5-44.4\%]; 7.6\% [4.9-11.5\%]).

\section{$D_{50}$ description/cycles}

Modeled distance at $50 \%$ detectability $\left(D_{50}\right)$ varied seasonally and was nominally greater mid-shelf than nearshore during both Cold-Pool-present and ColdPool-absent periods, ranging from 147 to $990 \mathrm{~m}$ and from 148 to $953 \mathrm{~m}$, respectively (Fig. 4). $\mathrm{D}_{50}$ was variable within-season, driven by reductions up to $800 \mathrm{~m}$ associated with noise from identified storms (see Mid-Atlantic Cold Pool, above). Substantial increases were not apparent after receiver tending on April 11 and August 8-9, 2018 (Fig. 4), suggesting that biofouling did not functionally affect $\mathrm{D}_{50}$.

Change point analysis identified two transitions at both the nearshore and mid-shelf sites. The first change point occurred on April 28, 2018 [95\% credible interval: April 26-May 1] at the deeper mid-shelf site and on May 1 [April 29-May 5] at the more-shallow nearshore site; the second occurred on Sept 8 [Sept 7-Sept 9] at the nearshore site and Sept 9 [Sept 8-Sept 9] at the midshelf site (Fig. 4). Estimated change points closely corresponded to the creation and destruction of the Cold Pool on May 2-5 and September 7, 2018. $\mathrm{D}_{50}$ increased from $609 \pm 128 \mathrm{~m}$ to $840 \pm 92 \mathrm{~m}$ (mean \pm standard deviation) and $592 \pm 116 \mathrm{~m}$ to $895 \pm 71 \mathrm{~m}$ at the first change point 


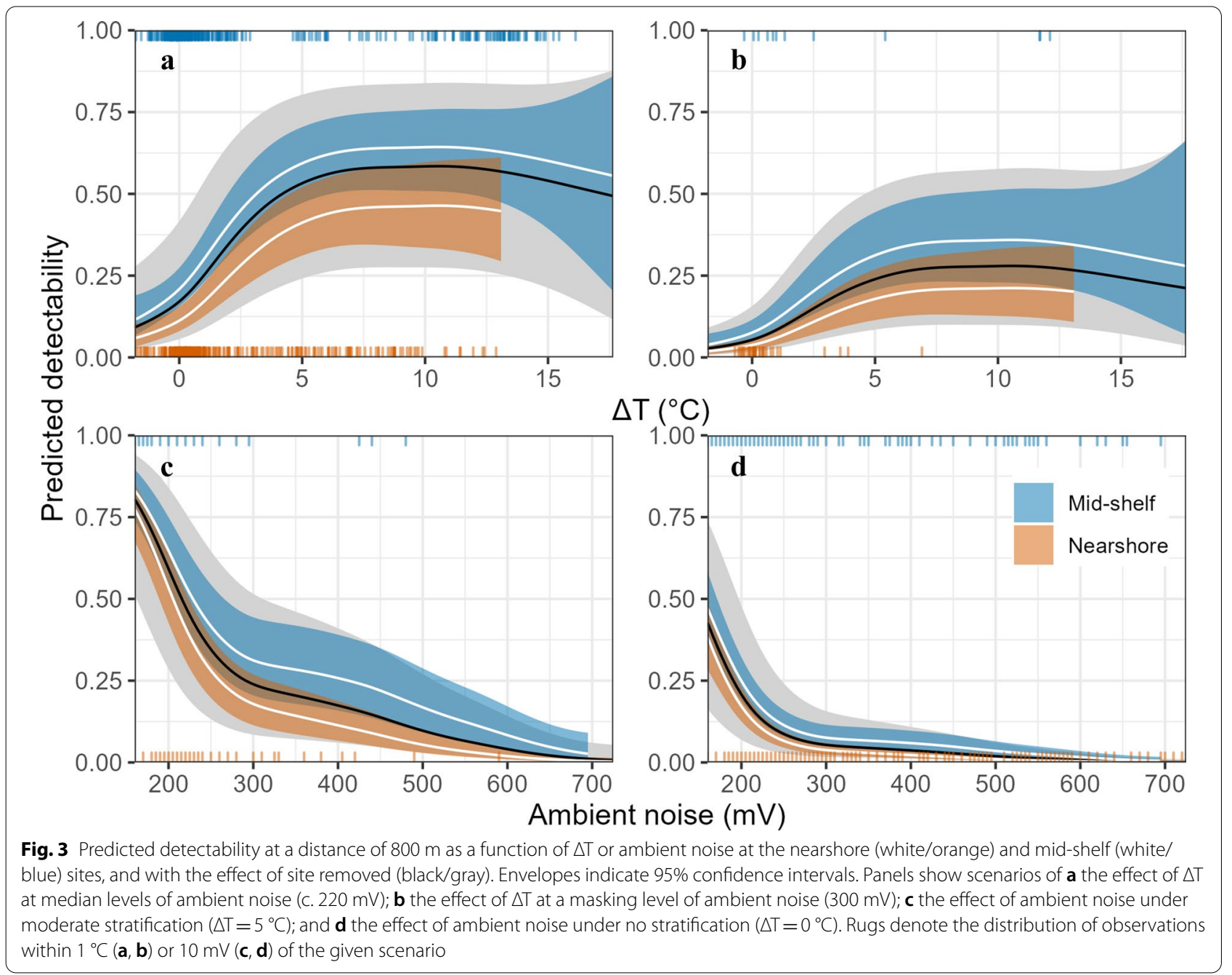

in the nearshore and mid-shelf sites, respectively, then decreased to $524 \pm 96$ and $589 \pm 86 \mathrm{~m}$ after the second.

The first change point was preceded by a 7 -day average $\Delta \mathrm{T}$ of $2.0^{\circ} \mathrm{C}$, with the second change point being followed by a $2.2{ }^{\circ} \mathrm{C} \Delta \mathrm{T} 7$-day average. A value of $2.0{ }^{\circ} \mathrm{C} \Delta \mathrm{T}$ was consistent with observed values demarcating the creation of the Cold Pool (Fig. 2) and increases in detectability suggested in the model results (Fig. 3). Mean temperature stratification and ambient noise differed between the three periods demarcated by change points, shifting from $0.2 \pm 0.6$ to $8.0 \pm 4.3^{\circ} \mathrm{C} \Delta \mathrm{T}$, then back to $0.2 \pm 1.4{ }^{\circ} \mathrm{C}$ $\Delta \mathrm{T}$; and from $273.2 \pm 110.6$ to $226.1 \pm 41.7 \mathrm{mV}$, then to $293.6 \pm 98.9 \mathrm{mV}$, respectively.

\section{Discussion}

\section{Stratification and detection range}

Through modeling the proportion of transmissions received per day at four different distances, ambient ultrasonic noise and temperature stratification emerged as the dominant variables controlling detectability at a given distance. Within this shelf environment, representative of the larger US Mid-Atlantic Bight, temperature stratification appeared as influential as noise, with the best model selecting both effects. The Mid-Atlantic Bight is typified by strong seasonality in temperature stratification and wind-driven noise events, and daily detection efficiencies were driven by their joint dynamics.

The best model predictions were within $19 \%$ of observed values at $800 \mathrm{~m}$, resulting in a window of $30-70 \%$ detectability when the true frequency of detection is $50 \%$. Although the model closely explained detectability during Cold-Pool-absent periods, the most unexplained variance occurred during Cold-Pool-present periods, suggesting that the interaction between noise and temperature stratification is unstable or that further terms could explain detection probability during times of temperature stratification. Detectability $>90 \%$ at $800 \mathrm{~m}$ was apparent during Cold-Pool-present periods, 


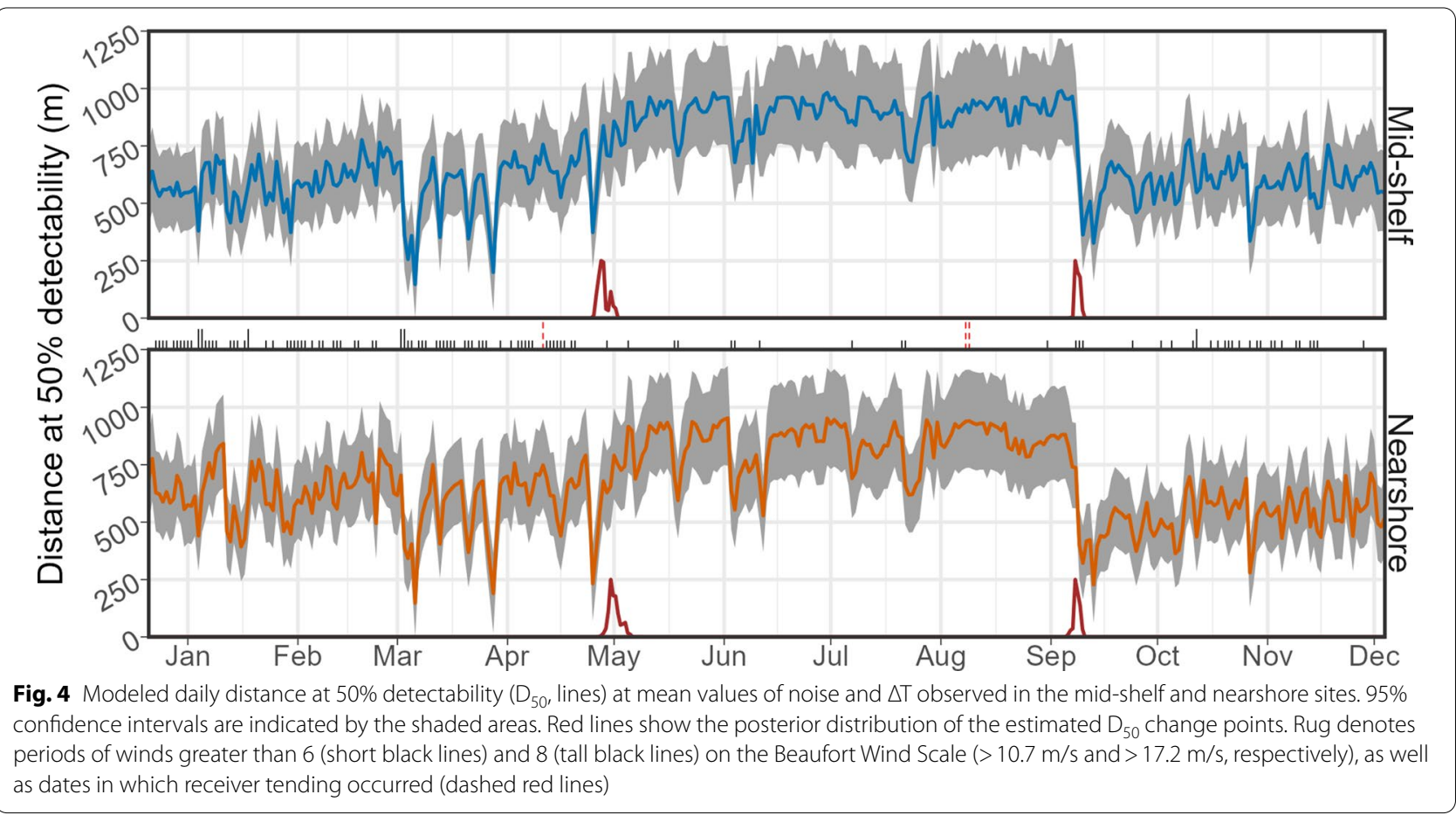

occurring in 3.4 and $33.5 \%$ of days in the nearshore and mid-shelf sites, respectively. As a result, the model is likely unable to accurately predict detectability at greater distances-an effect of this can be seen in the modelimposed upper limit of $D_{50}$ near $\sim 1250 \mathrm{~m}$ during the period of Cold Pool presence. An improved design would include test distances centered on either side of the expected D50, as well as one beyond the range limit [27].

Temperature stratification has been reported to decrease $[2,28-30]$ or cause little-to-no change $[25,31$, $32]$ in the detectability of acoustic telemetry transmissions; however, thermoclines on the SMAB shelf are much stronger and shallower than those reported in other detection range studies that incorporated the effect of temperature stratification (Table 2). In an analysis of detection probability conducted in the same area of the SMAB, Oliver et al. [32] found density stratification to have a significant negative effect on detection distance. However, this played a minor role in detectability as compared to other variables related to noise generation and stratification was only present for $24 \%$ of their study period, leading the authors to suggest that further exploration is needed. Klinard et al. [2], who used the $\Delta \mathrm{T}$ index of stratification utilized in the present study, reported

Table 2 Reported influence of a thermocline on detectability. Gradient, depth, and respective placement of transmitters and receivers across the thermocline were reported or calculated from reference figures

\begin{tabular}{|c|c|c|c|c|c|}
\hline \multirow[t]{2}{*}{ Reference } & \multirow[t]{2}{*}{ System } & \multicolumn{4}{|l|}{ Thermocline } \\
\hline & & Gradient $\left({ }^{\circ} \mathrm{C} / \mathrm{m}\right)$ & Depth (m) & $\begin{array}{l}\text { Transmitter- } \\
\text { receiver side }\end{array}$ & $\begin{array}{l}\text { Effect } \\
\text { on detectability }\end{array}$ \\
\hline Present study & Southern Mid-Atlantic Bight, USA & $1-2$ & $8-15$ & Same (below) & + \\
\hline Oliver et al. [32] & Southern Mid-Atlantic Bight, USA & & $15-20$ & Mix & - \\
\hline Jossart et al. [30] & Caribbean, USVI & 0.2 & $30-40$ & Within & - \\
\hline Singh et al. [33] & Kromme Bay, South Africa & 1 & $12-14$ & Mix & - \\
\hline Huveneers et al. [29] & New South Wales, Australia & 0.44 & $>20$ & Mix & - \\
\hline Cagua et al. [34] & Red Sea, Saudi Arabia & $>0.04$ & $<37$ & Mix & - \\
\hline Gjelland and Hedger [31] & Lake Skrukkebukta, Norway & & $10-21$ & Opposite & - \\
\hline Klinard et al. [2] & Lake Ontario & $>0.08$ & 11 & Mix & - \\
\hline
\end{tabular}


that temperature stratification played a minimal-tonegative role in detection distance within their array. The authors note that the array was not deployed during high-stratification months and that further investigation could show otherwise.

Studies that report a negative effect of thermocline presence often have transmitters or receivers within, or on different sides of, the thermocline. In these instances, detection requires signal transmission across a steep change in density, which can result in acoustic power loss [15]. In a study by Huveneers et al. [29], a transmitter was placed at mid-depth, with a suite of receivers suspended in the water column. Inspection of the partial effects of their model reveals that although a significant negative trend is apparent, there were instances when a significant positive effect can be noted-namely when the thermocline was shallow, placing transmitters and receivers far from a rapid change in density. This is not always the case however, as Singh et al. [33] explicitly investigated detectability on the same side of the thermocline, and found a negative effect. Further, Loher et al. [7] also observed rapid increases in detection probability attributed to destratification. In the present study, transmissions did not have to cross the thermocline as both transmitters and receivers were positioned near the sea bottom. As it is clear that detection probability is much reduced when crossing the thermocline, this study is likely more applicable to demersal species that spend the majority of time below the thermocline, such as Atlantic sturgeon, Atlantic cod, or black sea bass, than pelagic species, such as striped bass.

Though attributed to storms here, reduction in detectability could be attributed to other masking factors such as an increased presence of boat traffic or tagged fish. Increased summer boating and commercial shipping activity has been shown to substantially increase sonic noise within the SMAB $(10-800 \mathrm{~Hz},[35])$ to the degree that it can mask bioacoustic communication [36]. Shipping and boating traffic create noise dominating frequencies up to $40 \mathrm{kHz}$, and can span to $100 \mathrm{kHz}$ range and overlap with $69 \mathrm{kHz}$ transmitters [12, 37]. The nearshore site investigated here, particularly, is exposed to high levels of recreational boating traffic in the summer months [38]. However, Hildebrand [37] also notes that thermal noise is the dominant noise source above $60 \mathrm{kHz}$. Indeed, although there was increased shipping that could create transmission-masking noise, we recorded a decrease in masking ambient noise at $69 \mathrm{kHz}$ in the stratified summer months.

The presence of fish tagged with $69-\mathrm{kHz}$ transmitters could also result in reduced detection probability due to code collision [6]. At the investigated sites, the most common tagged species were Atlantic sturgeon and striped bass $(n>600)$, which were present from October through January and late-March through June [39]. As OctoberJanuary overlaps with a period of Cold Pool absence, a greater number of transmitting individuals in the area could have biased this period toward the comparatively low detectability reported in this study. The late-MarchJune period of transmitter presence, which includes the period of Cold Pool formation should also exhibit a low bias if code collision had a large effect. However, a bias toward low detectability during this period is not apparent-indeed, a change point toward increased detectability occurred in early May.

The distance when transmissions have an effectively random chance of detection, estimated as $\mathrm{D}_{50}$, is a common metric to investigate detection range. $D_{50}$ is intuitive when conceptualizing logistic acoustic power loss due to spreading over distance and simple to extract from nonlinear least squares [29], LOESS smoothing [40], generalized linear [41], and generalized additive models [42]. It also provides an answer to the question most investigators actually want answered: how far away could I have reliably heard this transmitter? $\mathrm{D}_{50}$ is often lower in marine than freshwater systems, ranging from 100$800 \mathrm{~m}$ in marine systems and exceeding $1000 \mathrm{~m}$ in freshwater $[2,6]$. In marine systems, most reported range tests have been conducted in subtropical reef systems, where stratification is not as extreme and topology and biogenic ultrasonic noise are much more influential [43]; $\mathrm{D}_{50}$ in these systems is frequently less than $400 \mathrm{~m} . \mathrm{D}_{50}$ in temperate marine systems, however, has been less-frequently investigated. In deep water systems off the Pacific coast of Alaska, Loher et al. [7] measured $\mathrm{D}_{50}$ greater than $1200 \mathrm{~m}$. On a shallow shelf system off the Atlantic coast of Georgia, Mathies et al. [14] attained $\mathrm{D}_{50}$ greater than $280 \mathrm{~m}$. Here, we report values for the shallow shelf of the Mid-Atlantic Bight straddling those reported in temperate climates, ranging from 0 to $1100 \mathrm{~m}$ with means of $580 \mathrm{~m}$ during non-stratified and $860 \mathrm{~m}$ during stratified periods. As transmitters were not implanted, $\mathrm{D}_{50}$ values reported in this study are likely over-estimated for studies utilizing surgically implanted transmitters [44]; results are most applicable to externally tagged fish or receiver arrays, themselves.

The exact relationship between ultrasonic sound propagation and an increase in detectability associated with temperature stratification is beyond the scope of this study, but likely lies within optic theory's Snell's Law [45]. As transmissions within a cold bottom layer propagate toward the surface, they come in contact with a rapid decrease in density associated with the thermocline. Using seasonal salinity differences [46] and observed temperatures, this corresponds to an increase in the speed of sound ranging from 4 to $6 \mathrm{~m} / \mathrm{s}$ at the $\mathrm{D}_{50}$ change 
point $\left(2{ }^{\circ} \mathrm{C} \Delta \mathrm{T}\right)$ to $69 \mathrm{~m} / \mathrm{s}$ at the maximum recorded value of $\Delta \mathrm{T}$ in this study $\left(17.4{ }^{\circ} \mathrm{C} \Delta \mathrm{T}\right)$ [47]. The transition from comparatively slower sound speed in the bottom layer to fast sound speed in the surface layer bends transmission rays back toward the bottom, and it is likely that some rays at shallow angles of incidence would be reflected back to the bottom layer. As there was minimal change in detectability beyond $4.2{ }^{\circ} \mathrm{C} \Delta \mathrm{T}$ at a given distance and noise level, there may be no functional effect of the strength stratification beyond this point, corresponding to a difference in the speed of sound greater than $14 \mathrm{~m} / \mathrm{s}$.

\section{Conclusion}

Temperature stratification within the US SMAB corresponded with $>33 \%$ increased detectability in bottom waters. Within this system, thermocline strength varied on an hourly to daily basis, resulting in highly variable detection ranges throughout the year studied. Flexible generalized linear or additive modeling can allow this variability to be incorporated into ecological or species distribution models to scale the number of records recorded through time [5]. Seeding telemetry arrays with long-term sync tags at assumed distances near 50\% and $0 \%$ detection frequency could calibrate the modeled transmission distance. To our knowledge, this study is the first to report and quantify an increase in detection range due to the onset of stratification, underlining that the detectability of underwater acoustic transmitters is unique to the time and location in which it is measured.

\section{Methods}

Both study sites had bottom types characteristic of the SMAB, with a relatively flat seabed dominated by sand and silt (>90\%; $[48,49])$, and were at depth representative of a migration corridor used by elasmobranchs, fishes, and turtles [39]. At each site, three receivers (VEMCO Ltd, VR2AR) were deployed-one each at 0, 250, and $800 \mathrm{~m}$ distances (Fig. 1). Each receiver was anchored by two $20.5-\mathrm{kg}$ lead plates and suspended $1 \mathrm{~m}$ above the seafloor by a $25-\mathrm{cm}$ hard trawl float. Transmitters internal to the receivers were set to transmit randomly every 9-11 min at the highest power $(160 \mathrm{~dB}$ re $1 \mu \mathrm{Pa} @ 1 \mathrm{~m})$ to mimic Vemco V16-xH transmitters $(158-162 \mathrm{~dB}$ re $1 \mu \mathrm{Pa} @ 1 \mathrm{~m})$, the most commonly deployed tag in animals transiting the SMAB [50]. On average, each receiver transmitted 6 times every hour, resulting in 18 recordable transmissions at $0 \mathrm{~m}$ and 12 recordable transmissions at 250,550 , and $800 \mathrm{~m}$, respectively. Due to an error in deployment, one transmitter at the mid-shelf site was not activated between April and August; as a result, half the daily replicates for the 250 and $500 \mathrm{~m}$ distances at the mid-shelf site were recorded during that period. The total number of transmissions and detection successes were summed for each receiver-distance-day combination. We did not account for code collision in this study; we assumed the effect of code collision was negligible as the range of daily recorded transmissions (136-150) was within the range of possible daily transmissions given the random transmission rate (130-160). In addition to immediately logging transmissions, receivers were set to record instantaneous measurements of bottom water temperature (BWT; ${ }^{\circ} \mathrm{C}$ ) and noise $(69 \mathrm{kHz}, \mathrm{mV})$ every hour. BWT and noise were aggregated to the daily level by taking the mean for each day. Arrays were deployed on December 19, 2017, and tended April 11 and August 8-9, 2018 via acoustic release and immediate replacement of a new receiver. All arrays were recovered on December 4, 2018.

Receiver-reported noise values in millivolts are not calibrated to a system sensitivity, and so average noise reported by the receivers cannot be directly and reliably converted to decibels. However, the provided noise in millivolts offers a self-referential metric of ambient noise at $69 \mathrm{kHz}$, wherein ambient noise levels above $300 \mathrm{mV}$ are often sufficient to mask tag transmissions [24].

As Cold Pool presence in the SMAB can be broadly represented by large differences between surface and bottom water temperatures $[19,20]$, we utilized the difference between satellite-derived sea surface temperature and in situ receiver-recorded bottom water temperature as an index of temperature stratification associated with the Cold Pool. In addition to the SMAB, this metric, $\Delta \mathrm{T}$, has previously been used as an index of thermal stratification in other systems $[2,51]$. Multi-scale ultra-high resolution sea surface temperature data [52], containing daily sea surface temperature at $0.01^{\circ}$ resolution $\left(\sim 1 \mathrm{~km}^{2}\right)$, were downloaded for the deployed time period from the CoastWatch West Coast Regional Node ERDDAP server [53]. The difference between satellite-observed sea surface temperature and observed daily mean bottom temperature in each array was summarized as $\Delta \mathrm{T}$. Higher absolute values of $\Delta \mathrm{T}$ represent a more-stratified water column, while lower values represent uniformity; higher positive values of $\Delta \mathrm{T}$ indicate Cold Pool presence and strength.

To investigate Cold Pool influence on detectability in the SMAB, daily detection success was modeled as a function of distance with various combinations of additive functions for $\Delta \mathrm{T}$ or $\mathrm{BWT}$, noise, and their interactions using a binomial generalized additive model (GAM) with logit link function and AR1 errors (Table 3). Distance was included in all models as logistic loss in acoustic power due to spherical or cylindrical spreading was assumed. BWT and $\Delta \mathrm{T}$ were alternately included in the model to investigate whether water column temperature stratification 
Table 3 Description of variables included in the model selection process

\begin{tabular}{|c|c|c|c|c|}
\hline Name & Units & Range & Type & Source \\
\hline Detection frequency & $\begin{array}{l}\text { Detections } \\
\text { transmissions }^{-1} \text { day }^{-1}\end{array}$ & $0-1$ & Response & Derived \\
\hline Ambient noise at $69 \mathrm{kHz}$ & $\mathrm{mV}$ & $171.3-703.9$ & Predictor & Recorded by receiver in situ \\
\hline Distance & $\mathrm{m}$ & $0-800$ & Predictor & $\begin{array}{l}\text { Derived from GPS location of } \\
\text { receiver deployment }\end{array}$ \\
\hline Sea surface temperature (SST) & ${ }^{\circ} \mathrm{C}$ & $3.5-27.4$ & Predictor & JPL MUR MEaSUREs Project [52] \\
\hline Bottom water temperature (BWT) & ${ }^{\circ} \mathrm{C}$ & $2.9-24.6$ & Predictor & Recorded by receiver in situ \\
\hline$\Delta \mathrm{T}$ & ${ }^{\circ} \mathrm{C}$ & $-1.7-17.4$ & Predictor & Derived: $\Delta \mathrm{T}=\mathrm{SST}-\mathrm{BWT}$ \\
\hline
\end{tabular}

better-explained variation in detection range than nearreceiver temperature, alone. A random intercept of receiver was included to account for possible variability in ultrasonic soundscapes between receiver location; the additive functions of BWT, $\Delta \mathrm{T}$, and noise were allowed to vary randomly by site around a global smooth. Model form was evaluated though inspection of residuals for correlation and non-normality; as residuals of the global model exhibited temporal autocorrelation, models were constructed with an AR1 error $(\rho=0.50)$.

Each receiver was assumed to detect itself $100 \%$ of the time; the recorded number of self-transmissions was used to calculate the proportion of detections received but not used in fitting the model. The best model was selected as that with lowest AIC. Model performance was evaluated using the RMSE of 5 repetitions of fivefold cross-validation. In this procedure, the data are randomly split into 5 subsets, or folds; 4 folds are used to fit the model, and the remaining fold is used to evaluate the deviance between predicted and observed values. This is repeated 5 times, using each fold in turn as a testing data. To provide a conservative estimate of model performance, the model was made more general by removing the influence of random effects after fitting, but before testing, the model during the cross-validation process. Model visualizations were conducted in reference to a distance of $800 \mathrm{~m}$, the farthest distance in the array with recorded detections. All GAMs were fit using the $m g c v$ package (version 1.8.31, [54]) in $\mathrm{R}$ (version 4.0.2, [55]).

To visualize variability in detection range through time, the best model was used to predict each day's distance at $50 \%$ detectability $\left(D_{50},[29]\right)$. Daily $D_{50}$ was estimated from the parameterized model:

$$
\begin{aligned}
& \operatorname{logit}(0.5)=\beta_{0}+\beta_{1} D_{50, \text { day }}+\beta_{2} \text { Receiver }+\sum_{n=1}^{N} f_{n}\left(x_{n, \text { day,site }}\right) \\
& D_{50, \text { day }}=\frac{-\left[\beta_{0}+\beta_{2} \text { Receiver }+\sum_{n=1}^{N} f_{n}\left(x_{n, \text { day,site })}\right)\right.}{\beta_{1}},
\end{aligned}
$$

where $\beta_{0}$ is the intercept, $\beta_{1}$ is the coefficient of the linear effect of distance, $\beta_{2}$ is the coefficient for the random effect of receiver, and $\sum_{n=1}^{N} f_{n}\left(x_{n, \text { day,site }}\right)$ is the sum of the $N$ additive effects chosen in the model selection process, evaluated for each site at the daily observed value of the corresponding predictor, $x_{n}$. Pointwise $95 \%$ confidence intervals for estimated $\mathrm{D}_{50}$ were calculated by simulation of the posterior distribution of the parameters. The number of change points in mean and variance of the resulting $\mathrm{D}_{50}$ time series were detected using the changepoint package in $\mathrm{R}$ (version 2.3.1, [56]) using the PELT algorithm and CROPS penalty, which identifies the optimal number of change points without a supervised choice of penalty value $[57,58]$. Locations of the identified number of change points were detected using Dirichlet priors ( $\alpha=$ number of identified change points) in the $m c p R$ package (version 0.3.0, [59]).

Data manipulation was conducted with the data.table (version 1.13.0, [60]) and sf (version 0.9.5, [61]) packages in $\mathrm{R}$, and figures were produced with the ggplot2 package (version 3.3.2, [62]). Data and $\mathrm{R}$ code used to conduct GAM fitting and $\mathrm{D}_{50}$ prediction procedures can be found in the Additional Files 1 and 2.

\section{Supplementary Information}

The online version contains supplementary material available at https://doi. org/10.1186/s40317-021-00233-3.

Additional file 1: Experimental dataset and README. (1) README: Metadata for the minimal dataset in "Additional file 1" sheet. (2) Additional file 1: Minimal dataset necessary to interpret, replicate and build upon the findings reported in the manuscript.

Additional file 2: Annotated R analysis. Annotated R code. Can be used to replicate the major findings reported in the manuscript using the data found in the "Additional file 1" sheet within Additional file 1.

\section{Abbreviations}

$\triangle T$ : Difference between SST and BWT; BWT: Bottom water temperature; ${ }^{\circ} \mathrm{C}$ : Degrees Celsius; $\mathrm{D}_{50}$ : Distance at 50\% detectability; GAM: Generalized additive model; m: Meters; mV: Millivolts; SMAB: Southern Mid-Atlantic Bight; RMSE: Root-mean-square error; SST: Sea surface temperature. 


\section{Acknowledgments}

We wish to thank Cory and Kerry Harrington of the FN Sea Born and Michael Hulme and Robert Nilsen of the R/N Rachel Carson for their assistance with acoustic receiver deployment and maintenance. We also wish to thank Caroline J. Wiernicki and Ella R. Rothermel who helped with receiver deployment and vetting of experimental design and data analysis.

\section{Authors' contributions}

DS secured funding for the experiment. MOB and DS designed and collected the data for the experiment. MOB analyzed and interpreted data for the experiment. MOB drafted the manuscript with input and review from DS. Both authors read and approved the final manuscript.

\section{Funding}

Project funding was provided by the US Department of the Interior, Bureau of Ocean Energy Management (BOEM), Office of Renewable Energy Programs, Sterling, VA, under Cooperative Agreement Number M16AC00008 to DHS and the University of Maryland Center for Environmental Science Chesapeake Biological Laboratory. The funding agency was given the opportunity to review the study design, preliminary results, and manuscript. The funding agency did not participate in analysis or manuscript preparation.

\section{Availability of data and materials}

The dataset supporting the conclusions of this article is included within the article (and its Additional Files 1 and 2).

\section{Ethics approval and consent to participate}

Not applicable.

\section{Consent for publication}

Not applicable.

\section{Competing interests}

The authors declare that they have no competing interests.

Received: 21 August 2020 Accepted: 2 February 2021

Published online: 11 February 2021

\section{References}

1. Kessel ST, Cooke SJ, Heupel MR, Hussey NE, Simpfendorfer CA, Vagle $S$, et al. A review of detection range testing in aquatic passive acoustic telemetry studies. Rev Fish Biol Fish. 2014:24:199-218.

2. Klinard NV, Halfyard EA, Matley JK, Fisk AT, Johnson TB. The influence of dynamic environmental interactions on detection efficiency of acoustic transmitters in a large, deep, freshwater lake. Anim Biotelemetry. 2019;7:17.

3. Gjelland $K \varnothing$, Hedger RD. On the parameterization of acoustic detection probability models. Reynolds J, editor. Methods Ecol Evol. 2017;8:1302-4.

4. Kraus RT, Holbrook CM, Vandergoot CS, Stewart TR, Faust MD, Watkinson DA, et al. Evaluation of acoustic telemetry grids for determining aquatic animal movement and survival. Auger-Méthé $M$, editor. Methods Ecol Evol. 2018;9:1489-502.

5. Secor D, O'Brien M, Rothermel E, Wiernicki C, Bailey H. Movement and habitat selection by migratory fishes within the Maryland Wind Energy Area and adjacent reference sites. SterI VA US Dep Inter Bur Ocean Energy Manag Off Renew Energy Programs OCS Study BOEM. 2020;30:109.

6. Hayden TA, Holbrook CM, Binder TR, Dettmers JM, Cooke SJ, Vandergoot CS, et al. Probability of acoustic transmitter detections by receiver lines in Lake Huron: results of multi-year field tests and simulations. Anim Biotelemetry. 2016;4:19.

7. Loher T, Webster RA, Carlile D. A test of the detection range of acoustic transmitters and receivers deployed in deep waters of Southeast Alaska, USA. Anim Biotelemetry. 2017;5:27.

8. Au WWL, Hastings MC. Signal Recording and Data Acquisition. Princ Mar Bioacoustics. New York, NY: Springer US; 2008. p. 121-75.

9. Urick RJ. Principles of underwater sound-2. ed. New York, N.Y. (USA) McGraw-Hill Book; 1975;

10. Katsnelson B, Petnikov V, Lynch J. Fundamentals of Shallow Water Acoustics. Springer Science \& Business Media; 2012.
11. Kuperman WA, Lynch JF. Shallow-water acoustics. Phys Today Citeseer. 2004:57:55-61.

12. Veirs $S$, Veirs $V$, Wood JD. Ship noise extends to frequencies used for echolocation by endangered killer whales. PeerJ. 2016:4:e1657.

13. Payne NL, Gillanders BM, Webber DM, Semmens JM. Interpreting diel activity patterns from acoustic telemetry: the need for controls. Mar Ecol Prog Ser. 2010:419:295-301.

14. Mathies N, Ogburn M, McFall G, Fangman S. Environmental interference factors affecting detection range in acoustic telemetry studies using fixed receiver arrays. Mar Ecol Prog Ser. 2014;495:27-38.

15. Song A, Badiey M, Song HC, Hodgkiss WS. Impact of source depth on coherent underwater acoustic communications. J Acoust Soc Am. 2010;128:555-8.

16. Bangley CW, Curtis TH, Secor DH, Latour RJ, Ogburn MB. Identifying important juvenile dusky shark habitat in the northwest Atlantic ocean using acoustic telemetry and spatial modeling. Mar Coast Fish. 2020;12:348-63.

17. Patel SH, Barco SG, Crowe LM, Manning JP, Matzen E, Smolowitz RJ, et al. Loggerhead turtles are good ocean-observers in stratified midlatitude regions. Estuar Coast Shelf Sci. 2018:213:128-36.

18. Li Y, Fratantoni PS, Chen C, Hare JA, Sun Y, Beardsley RC, et al. Spatiotemporal patterns of stratification on the Northwest Atlantic shelf. Prog Oceanogr. 2015;134:123-37.

19. Lentz SJ. Seasonal warming of the Middle Atlantic Bight Cold Pool. J Geophys Res Oceans. 2017;122:941-54.

20. Chen Z, Curchitser E, Chant R, Kang D. Seasonal variability of the Cold Pool over the Mid-Atlantic Bight continental shelf. J Geophys Res Oceans. 2018;123:8203-26.

21. Forsyth J, Gawarkiewicz G, Andres M, Chen K. The interannual variability of the breakdown of fall stratification on the New Jersey shelf. J Geophys Res Oceans. 2018;123:6503-20.

22. Glenn SM, Miles TN, Seroka GN, Xu Y, Forney RK, Yu F, et al. Stratified coastal ocean interactions with tropical cyclones. Nat Commun. 2016;7:10887.

23. Secor DH, Zhang F, O'Brien MHP, Li M. Ocean destratification and fish evacuation caused by a Mid-Atlantic tropical storm. Oliver M, editor. ICES J Mar Sci. 2019;76:573-84.

24. Receiver Noise Measurements [Internet]. Innovasea. [cited 2020 Aug 11]. https://go.innovasea.com/receiver_noise.pdf

25. Cimino M, Cassen M, Merrifield S, Terrill E. Detection efficiency of acoustic biotelemetry sensors on Wave Gliders. Anim Biotelemetry. 2018:6:16.

26. Harrison XA, Donaldson L, Correa-Cano ME, Evans J, Fisher DN, Goodwin CE, et al. A brief introduction to mixed effects modelling and multi-model inference in ecology. PeerJ Inc. 2018;6:e4794.

27. Brownscombe JW, Griffin LP, Chapman JM, Morley D, Acosta A, Crossin GT, et al. A practical method to account for variation in detection range in acoustic telemetry arrays to accurately quantify the spatial ecology of aquatic animals. Codling E, editor. Methods Ecol Evol. 2020;11:82-94.

28. How JR, de Lestang S. Acoustic tracking: issues affecting design, analysis and interpretation of data from movement studies. Mar Freshw Res. 2012;63:312.

29. Huveneers C, Simpfendorfer CA, Kim S, Semmens JM, Hobday AJ, Pederson $\mathrm{H}$, et al. The influence of environmental parameters on the performance and detection range of acoustic receivers. Reynolds J, editor. Methods Ecol Evol. 2016;7:825-35

30. Jossart J, Nemeth RS, Primack A, Stolz R. Extreme passive acoustic telemetry detection variability on a mesophotic coral reef. United States Virgin Islands Mar Biol. 2017;164:180.

31. Gjelland $K \varnothing$, Hedger RD. Environmental influence on transmitter detection probability in biotelemetry: developing a general model of acoustic transmission. Rands S, editor. Methods Ecol Evol. 2013:4:665-74.

32. Oliver MJ, Breece MW, Haulsee DE, Cimino MA, Kohut J, Aragon D, et al. Factors affecting detection efficiency of mobile telemetry Slocum gliders. Anim Biotelemetry. 2017;5:14.

33. Singh L, Downey NJ, Roberts MJ, Webber DM, Smale MJ, van den Berg MA, et al. Design and calibration of an acoustic telemetry system subject to upwelling events. Afr J Mar Sci. 2009;31:355-64.

34. Cagua EF, Berumen ML, Tyler EHM. Topography and biological noise determine acoustic detectability on coral reefs. Coral Reefs. 2013:32:1123-34. 
35. Bailey H, Rice AN, Wingfield JE, Hodge KB, Estabrook B, Hawthorne D, et al. Determining habitat use by marine mammals and ambient noise levels using passive acoustic monitoring offshore of Maryland. Sterl VA US Dep Inter Bur Ocean Energy Manag OCS Study BOEM. 2019;1 8:232.

36. Fouda L, Wingfield JE, Fandel AD, Garrod A, Hodge KB, Rice AN, et al. Dolphins simplify their vocal calls in response to increased ambient noise. Biol Lett. 2018;14:20180484.

37. Hildebrand JA. Anthropogenic and natural sources of ambient noise in the ocean. Mar Ecol Prog Ser. 2009;395:5-20.

38. Mid-Atlantic Ocean Data Portal - Marine Planner [Internet]. [cited 2021 Jan 24]. Available from: https://portal.midatlanticocean.org/

39. Rothermel ER, Balazik MT, Best JE, Breece MW, Fox DA, Gahagan BI, et al. Comparative migration ecology of striped bass and Atlantic sturgeon in the US Southern mid-Atlantic bight flyway. Mourier J, editor. PLOS ONE. 2020;15:e0234442.

40. Oh BZL, Thums M, Babcock RC, Meeuwig JJ, Pillans RD, Speed C, et al. Contrasting patterns of residency and space use of coastal sharks within a communal shark nursery. Mar Freshw Res. 2017;68:1501.

41. Selby TH, Hart KM, Fujisaki I, Smith BJ, Pollock CJ, Hillis-Starr Z, et al. Can you hear me now? Range-testing a submerged passive acoustic receiver array in a Caribbean coral reef habitat. Ecol Evol. 2016;6:4823-35.

42. Scherrer SR, Rideout BP, Giorli G, Nosal E-M, Weng KC. Depth- and rangedependent variation in the performance of aquatic telemetry systems: understanding and predicting the susceptibility of acoustic tag-receiver pairs to close proximity detection interference. PeerJ. 2018;6:e4249.

43. Welsh JQ, Fox RJ, Webber DM, Bellwood DR. Performance of remote acoustic receivers within a coral reef habitat: implications for array design. Coral Reefs. 2012;31:693-702.

44. Dance MA, Moulton DL, Furey NB, Rooker JR. Does transmitter placement or species affect detection efficiency of tagged animals in biotelemetry research? Fish Res. 2016:183:80-5.

45. Hovem JM. Ray Trace Modeling of Underwater Sound Propagation. In: Beghi MG, editor. Model Meas Methods Acoust Waves Acoust Microdevices. InTech; 2013. p. 573-98.

46. Richaud B, Kwon Y-O, Joyce TM, Fratantoni PS, Lentz SJ. Surface and bottom temperature and salinity climatology along the continental shelf off the Canadian and U.S. East Coasts. Cont Shelf Res. 2016;124:165-81.

47. Medwin H. Speed of sound in water: A simple equation for realistic parameters. J Acoust Soc Am. Acoustical Society of America; 1975;58:1318-9.

48. Steimle FW, Zetlin C. Reef habitats in the middle Atlantic bight: abundance, distribution, associated biological communities, and fishery resource use. Mar Fish Rev. 2000;62:24-42.
49. Guida V, Drohan A, Johnson D, Pessutti J, Fromm S, McHenry J. Report on benthic habitats in the Maryland Wind Energy Area. Rep US Dep Inter Bur Ocean Energy Manag Interag Agreem M13PG0001902 Sandy Hook NJ Northeast Fish Sci Cent. 2015;

50. The Atlantic Cooperative Telemetry Network [Internet]. Available from: https://www.theactnetwork.com/

51. Li J, Li G, Xu J, Dong P, Qiao L, Liu S, et al. Seasonal evolution of the Yellow Sea Cold Water Mass and its interactions with ambient hydrodynamic system. J Geophys Res Oceans. 2016;121:6779-92.

52. JPL MUR MEaSUREs Project. GHRSST Level 4 MUR Global Foundation Sea Surface Temperature Analysis (v4.1) [Internet]. PO.DAAC, CA, USA: NASA; 2015 [cited 2018 Dec 11]. http://podaac.jpl.nasa.gov/dataset/ MUR-JPL-L4-GLOB-V4.1

53. Simons RA. ERDDAP [Internet]. Monterey, CA: NOAA/NMFS/SWFSC/ERD; 2019. Available from: https://coastwatch.pfeg.noaa.gov/erddap

54. Wood SN. Fast stable restricted maximum likelihood and marginal likelihood estimation of semiparametric generalized linear models. J R Stat Soc B. 2011;73:3-36.

55. R Core Team. R: A Language and Environment for Statistical Computing. Vienna, Austria: R Foundation for Statistical Computing; 2020.

56. Killick R, Haynes K, Eckley IA. changepoint: An R package for changepoint analysis. 2019.

57. Killick R, Fearnhead P, Eckley IA. Optimal detection of changepoints with a linear computational cost. J Am Stat Assoc. Taylor \& Francis; 2012;107:1590-8.

58. Haynes K, Eckley IA, Fearnhead P. Computationally Efficient Changepoint Detection for a Range of Penalties. J Comput Graph Stat. Taylor \& Francis; 2017;26:134-43.

59. Lindeløv JK. mcp: An R Package for Regression With Multiple Change Points. OSF Prepr. 2020;

60. Dowle M, Srinivasan A. data.table: Extension of 'data.frame'. 2020

61. Pebesma E. Simple Features for R: Standardized Support for Spatial Vector Data. R J. 2018;10:439-46.

62. Wickham H. ggplot2: Elegant Graphics for Data Analysis. New York: Springer-Verlag; 2016.

\section{Publisher's Note}

Springer Nature remains neutral with regard to jurisdictional claims in published maps and institutional affiliations.
Ready to submit your research? Choose BMC and benefit from:

- fast, convenient online submission

- thorough peer review by experienced researchers in your field

- rapid publication on acceptance

- support for research data, including large and complex data types

- gold Open Access which fosters wider collaboration and increased citations

- maximum visibility for your research: over $100 \mathrm{M}$ website views per year

At BMC, research is always in progress.

Learn more biomedcentral.com/submissions 